\title{
Long-Term Substance Use Can Cause Irreversible Photopic Vision Changes in Substance Use Disorder in Remission
}

\author{
Oguzhan Bekir Egilmez ${ }^{1}$, Mehmet Hamdi Orum ${ }^{2}$, Ali Kustepe $^{3}$, \\ Ayse Sevgi Karadag ${ }^{4}$, and Aysun Kalenderoglu ${ }^{1}$ \\ ${ }^{1}$ Department of Psychiatry, Adiyaman University, Faculty of Medicine, Adiyaman, Turkey \\ ${ }^{2}$ Psychiatry Clinic, Kahta State Hospital, Adiyaman, Turkey \\ ${ }^{3}$ Adiyaman University Training and Research Hospital, Adiyaman, Turkey \\ ${ }^{4}$ Department of Ophthalmology, Adiyaman University, Faculty of Medicine, Adiyaman, Turkey
}

Objective Substance use has such effects on pupil diameter. Although there is knowledge about the acute effects of substances on pupils, studies showing their chronic effects are limited. The aim of the present study was to evaluate the effect of long-term substance use on scotopic, mesopic, and photopic vision.

Methods The present study with cross-sectional desgn was conducted at the Adiyaman Training and Research Hospital for Psychiatry in Adiyaman. This study involved 110 substance use disorder (SUD) patients and 46 healthy volunteers as the control. The parameters were measured and recorded automatically by a device.

Results The mean age was $23.44 \pm 5.53$ years in the SUD group and $24.26 \pm 5.38$ years in healthy controls $(\mathrm{p}=0.420)$. The mean age of onset of the substance was $17.74 \pm 3.89$ years and the mean duration of substance use was $3.54 \pm 2.9$ years. It was determined that the patients had not used any substance for a mean of $121.73 \pm 117.49$ days. There was no significant difference between patient and control groups in terms of scotopic and mesopic measurements of both eyes $(\mathrm{p}>0.05)$. Photopic measurements were significantly higher in the patient group than in the control group $(\mathrm{p}<0.05)$. Photopic measurements were significantly higher in the opioid, cannabis, ecstasy, and multiple substance use groups than in the control group $(\mathrm{p}<0.05)$.

Conclusion The most important topic of this study is that photopic vision is permanently impaired in patients with a history of chronic substance use. This was attributed to disrupted sympathetic-parasympathetic hierarchy.

Psychiatry Investig 2020;17(10):1037-1043

Key Words Pupil diameter, Photopic, Scotopic, Mesophic, Substance use disorder.

\section{INTRODUCTION}

A colored circular muscle, the iris, is perforated by a central opening, the pupil, which is shifted slightly toward the nasal side. The main function of the iris is to regulate the amount of light reaching the retina, which it does by constantly adjusting the pupil size. This adjustment is effected by a muscle system composed of a circular part, the sphincter pupillae, and a radial part, the dilator pupillae. The pupil ranges in size from $7.5-8$

Received: February 20, 2020 Revised: July 6, 2020

Accepted: September 10, 2020

$\triangle$ Correspondence: Mehmet Hamdi Orum, MD

Psychiatry Clinic, Kahta State Hospital, Yavuz Selim Street, No: 39, Kahta, Adiyaman 02100, Turkey

Tel: +90 41621610 15/1186, E-mail: mhorum@hotmail.com

(a) This is an Open Access article distributed under the terms of the Creative Commons Attribution Non-Commercial License (https://creativecommons.org/licenses/by$\mathrm{nc} / 4.0$ ) which permits unrestricted non-commercial use, distribution, and reproduction in any medium, provided the original work is properly cited. $\mathrm{mm}$ at full mydriasis to $1.5-2 \mathrm{~mm}$ at full miosis. This means that the area of the pupil $\left(\pi r^{2}\right)$, and thus the amount of light admitted to the eye, can vary by a factor of 36 . At maximum constriction the fibers of the sphincter pupillae are shortened by $87 \%$ relative to their length in the resting state, a property possessed by no other smooth muscle in the human body. In infants, the pupil is smaller and reaches its normal diameter at the age of $7-8$, and tends to be smaller in the elderly. ${ }^{1-3}$

Apart from the function of controlling the size of the pupil, the iris that has sympathetic and parasympathetic innervation contributes to the reduction of aberrations and the depth of focus. Any pathology that may develop in the arch of the pupil reflex disrupts the pupil's response to light. ${ }^{4,5}$ The most important factors affecting the pupil diameter are the intensity of light reaching the retina and accommodation. ${ }^{5,6}$ In addition, many different factors such as age, attention level, changes in parasympathetic and sympathetic efferent pathways and to- 
nus dominance affect pupil diameter. ${ }^{4,6}$ Pupillary diameter control is mainly achieved by autonomic control, in which the sympathetic and parasympathetic system plays a role. Miosis occurs when the parasympathetic system is activated and mydriasis occurs when the sympathetic system is activated. ${ }^{7}$

The sympathetic and parasympathetic system has a hierarchical order. Roughly, the stimulus from the periphery moves to the spinal cord, brain stem, hypothalamus and eventually to the cerebral cortex, respectively. Although the sympatheticparasympathetic activation cycle is regulated regularly under physiological conditions, it can be affected by any pharmacological agent that affects this cycle. This affect the pupil diameter due to the presence of both adrenergic and serotergic receptors in the retina, as well as the multiple complex pathways in the central nervous system. ${ }^{8}$ It is known that sedatives, anesthetics, psychostimulants, as well as opioids and cannabinoids, have different effects on pupil diameter.-11 Delta-9-tetrahydrocannabinol (THC), also known as the cannabis and marijuana, rapidly distributes from blood and can cause various effects on pupil size. Blood 11-hydroxy-THC concentrations were significantly related to pupil sizes in all lighting conditions. The effect of cannabis on pupil diameter is controversial. In several studies, a reduced pupil diameter was measured after cannabis intake, ${ }^{12}$ but others have found dilated pupils. ${ }^{9}$ Opioid and its derivatives cause miosis through parasympathetic system activation. In addition, an advanced miotic reaction called pinpoint pupil is seen in opioid intoxication. ${ }^{13}$ It has been shown that the miotic effect may vary depending on the dose in opioid use and also there is a correlation between plasma concentration and pupil diameter changes. ${ }^{14}$

Although there are studies evaluating pupil with substance effect, there are not enough studies evaluating pupil who have used substance in the past but are not currently affected by substance. We hypothesize that chronic substance use has permanent effects on pupil diameter. The aim of this study was to evaluate the pupil diameters of subjects with a history of substance use disorder (SUD) who are not currently under the influence of a substance and to discuss the pathophysiological mechanisms in the light of literature.

\section{METHODS}

\section{Study design}

This was a case-control study comparing 110 male patients diagnosed with SUD according to Diagnostic and Statistical Manual of Mental Disorders, 5th Edition (DSM-5) ${ }^{15}$ and 46 healthy males. The diagnosis of SUD was made by an experienced psychiatrist. The study group consisted of patients who were followed up at the outpatient clinic of Alcohol-Drug Addiction Research and Training Centers (AMATEM) in our hospital. Patients admitted to the AMATEM outpatient clinic are examined once every 15 days. Toxicological analysis of urine is used to determine whether substance use is present. The patients included in our study consisted of patients who had no substance detected in urine and had no withdrawal or intoxication symptoms. After being seen during the baseline visit by the treating psychiatrist, each patient's eligibility for the study was evaluated, and if they were eligible, they were invited to participate in the study. The control group consisted of healthy volunteers without a history of a SUD who were recruited from the hospital staff. The sociodemographical variables and substance use characteristics were obtained. This study was approved by the Ethics Committee of our University Training and Research Hospital (Adiyaman University Ethics Committee, Date: 23/03/2016, Number: 2016/2-7).

\section{Inclusion and exclusion criteria}

Male patients with SUD who were between 18 and 35 years of age and who were diagnosed according to the DSM-5 criteria were included. Persons who have used any of the substances in the last 8 weeks have not been taken to study. $\mathrm{Pa}$ tients and controls with insufficient or incomplete data were not included in the study. Persons with organic disease or those with the potential to affect the measured parameters (e.g., drug use, hypertension, diabetes mellitus, coronary artery disease, cancer, hyperlipidemia, infectious diseases, pregnancy, and rheumatologic diseases) were excluded. Patients with refraction errors $\geq 1$ prism dioptre were also excluded. Both the patient and the control groups were examined in the ophthalmology clinic and best corrected visual acuity, intraocular pressure, slit lamb bio-microscopy, and fundus examination by eye dilatation was measured. Patients and controls with normal eye findings were included. The group of healthy controls did not have hypertension, diabetes mellitus, severe neurological, immunological or systemic diseases which may affect the results. Local ethics committee approval was obtained, and all study participants provided written informed consent.

\section{Pupil diameter measurement}

The measurements were performed in light, soft light and dark environments with the pupillometer system of a calibrated device. The brightness of the light sent to the eye during the test was adjusted by the computer. Pupil diameter measured in light is called as photopic, called as mesopic in soft light, and called as scotopic in dark. Pupil measurements were performed with the Sirius 3D Rotating Scheimpflug Camera \& Topography System (Costruzioni Strumenti Oftalmici, Florence, Italy) (Figure 1), which performed anterior segment analysis using a combination of scheimpflug camera and placido disc technique. Scotopic measurements were measured at 0.04 


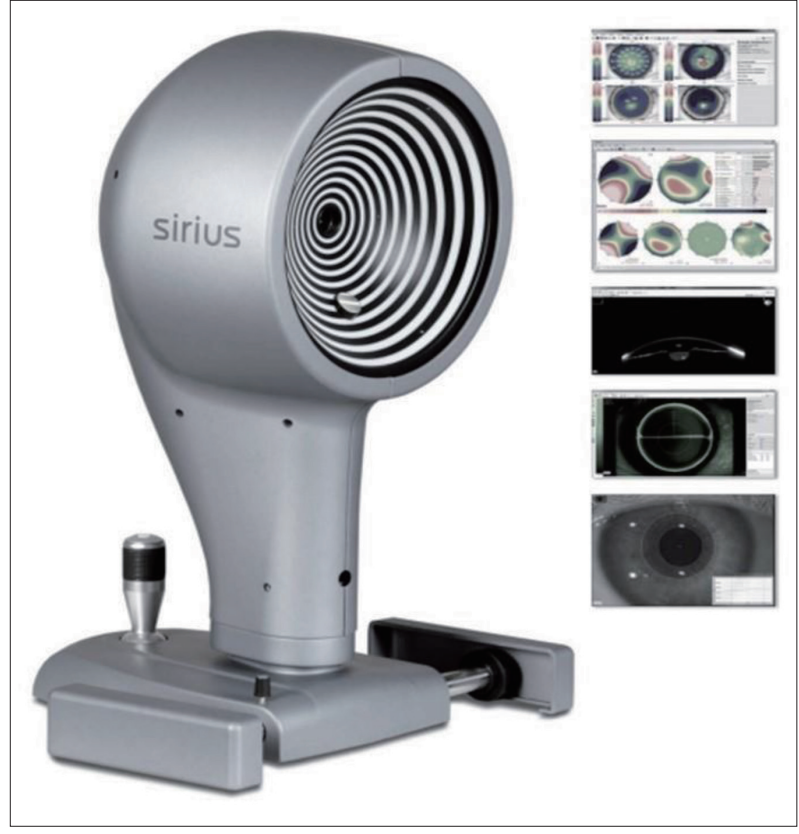

Figure 1. The diagnostic device.

lux, mesopic measurements at 4 lux, and photopic measurements at 50 lux.

\section{Statistical analyses}

Statistical analyses were performed using SPSS 22.0 package program (IBM Corp., Armonk, NY, USA). The mean \pm standard deviation and percentages were used as descriptive statistics. The chi-square test was used to compare categorical variables. The normality of the data was tested using the KolmogorovSmirnov test. An independent samples t-test was used to compare two normally distributed variables and the Mann-Whitney $\mathrm{U}$ test was used to compare two non-normally distributed variables. The relationship between spherical equivalent values and pupil diameter measurements was investigated by spearman correlation analysis. A value of less than 0.05 was considered statistically significant.

\section{RESULTS}

The mean ages in the SUD group and control groups were $23.44 \pm 5.53$ years and $24.26 \pm 5.38$ years, respectively and it was not significant $(\mathrm{p}=0.420)$. The socio-demographic features of the SUD and control groups are shown in Table 1. There was a significant difference between SUD and control groups in terms of marital status, education level, working status and forensic history $(\mathrm{p}<0.05)$ (Table 1$)$.

There were 30 (27.3\%) opioid use disorder (OUD), 31 (28.2\%) cannabis use disorder (CUD), 32 (29.1\%) ecstasy use disorder (EUD), 17 (15.4\%) multiple substance use disorder
Table 1. Sociodemographic data of patient and control groups

\begin{tabular}{|c|c|c|c|}
\hline & $\begin{array}{c}\text { Patient } \\
(\mathrm{N}=110)\end{array}$ & $\begin{array}{l}\text { Control } \\
(\mathrm{N}=46)\end{array}$ & $\mathrm{p}$ value \\
\hline Age (years) & $23.44 \pm 5.53$ & $24.26 \pm 5.38$ & 0.420 \\
\hline Marital status (\%) & & & $0.023^{*}$ \\
\hline Married & $21(19.1)$ & $18(39.1)$ & \\
\hline Single & $87(79.1)$ & $28(60.9)$ & \\
\hline Widow & $2(1.8)$ & $0(0.0)$ & \\
\hline Education status (\%) & & & $0.000^{*}$ \\
\hline Primary & $6(5.5)$ & $0(0.0)$ & \\
\hline Secondary & $77(70.0)$ & $1(2.2)$ & \\
\hline High & $23(20.9)$ & $16(34.8)$ & \\
\hline University & $4(3.6)$ & $29(63.0)$ & \\
\hline Working status (\%) & & & $0.008^{*}$ \\
\hline Yes & $90(81.8)$ & $45(97.8)$ & \\
\hline No & $20(18.2)$ & $1(2.2)$ & \\
\hline Forensic history (\%) & & & $0.000^{*}$ \\
\hline Yes & $79(71.8)$ & $1(2.2)$ & \\
\hline No & $31(28.2)$ & $45(97.8)$ & \\
\hline
\end{tabular}

(MDUD) in SUD group. The mean age of onset of the substance was $17.74 \pm 3.89$ years and the mean duration of substance use was $3.54 \pm 2.9$ years. Fifteen patients $(13.6 \%)$ had buprenorphine plus naloxone use history. It was determined that the patients had not used any substance for a mean of $121.73 \pm 117.49$ days.

There was no significant difference between SUD and control groups in terms of scotopic and mesopic measurements of both eyes ( $p>0.05)$. Photopic measurements were significantly higher in the SUD group than in the control group $(\mathrm{p}<$ 0.05 ) (Table 2). There was no significant difference between OUD and control groups; CUD and control groups; MDUD and control groups; EUD and control groups in terms of scotopic and mesopic measurements of both eyes ( $p>0.05)$. Photopic measurements were significantly higher in the OUD, CUD, EUD, and MDUD groups than in the control group $(\mathrm{p}<0.05)$ (Tables 3-6).

\section{DISCUSSION}

This study is important in terms of being the first study to measure the sub-parameters of pupil diameter at different light intervals in patients with long-term substance use who are not currently under the influence of a substance. The first important finding in our study was that the photopic measurements of the patient group were significantly larger than the control group. In the analysis conducted according to sub- 
stance subgroups, this was found to be the case for all drugs.

It is known that opioid use has a dose-related miotic effect in many studies. At high doses, the miotic effect increases and

Table 2. Pupil diameters of patient and control groups

\begin{tabular}{lll}
\hline Parameter & Mean \pm SD & p value \\
\hline Right scotopic & & 0.847 \\
Patient $(\mathrm{N}=110)$ & $5.80 \pm 1.13$ & \\
Control $(\mathrm{N}=46)$ & $5.77 \pm 0.94$ & \\
Right mesophic & & 0.107 \\
Patient $(\mathrm{N}=110)$ & $5.24 \pm 1.08$ & \\
Control $(\mathrm{N}=46)$ & $4.94 \pm 1.02$ & \\
Right photopic & & \\
Patient $(\mathrm{N}=110)$ & $4.23 \pm 0.86$ & \\
Control $(\mathrm{N}=46)$ & $3.73 \pm 0.74$ & 0.471 \\
Left scotopic & & \\
Patient $(\mathrm{N}=110)$ & $5.47 \pm 1.15$ & 0.106 \\
Control $(\mathrm{N}=46)$ & $5.32 \pm 1.06$ & \\
Left mesophic & & \\
Patient $(\mathrm{N}=110)$ & $4.98 \pm 1.09$ & \\
Control $(\mathrm{N}=46)$ & $4.68 \pm 0.92$ & \\
Left photopic & & \\
Patient $(\mathrm{N}=110)$ & $4.10 \pm 0.85$ & \\
Control $(\mathrm{N}=46)$ & $3.81 \pm 0.77$ & \\
* $<0.05 . \mathrm{SD}:$ standard deviation &
\end{tabular}

Table 3. Pupil diameters of opioid and control groups

\begin{tabular}{lll}
\hline Parameter & Mean \pm SD & p value \\
\hline Right scotopic & & 0.587 \\
Patient $(\mathrm{N}=30)$ & $5.92 \pm 1.29$ & \\
Control $(\mathrm{N}=46)$ & $5.77 \pm 0.94$ & \\
Right mesophic & & 0.184 \\
Patient $(\mathrm{N}=30)$ & $5.33 \pm 1.13$ & \\
Control $(\mathrm{N}=46)$ & $4.94 \pm 1.02$ & $0.009^{*}$ \\
Right photopic & & \\
Patient $(\mathrm{N}=30)$ & $4.30 \pm 0.84$ & 0.216 \\
Control $(\mathrm{N}=46)$ & $3.73 \pm 0.74$ & \\
Left scotopic & & \\
Patient $(\mathrm{N}=30)$ & $5.62 \pm 1.10$ & \\
Control $(\mathrm{N}=46)$ & $5.32 \pm 1.06$ & \\
Left mesophic & & \\
Patient $(\mathrm{N}=30)$ & $5.04 \pm 0.99$ & \\
Control $(\mathrm{N}=46)$ & $4.68 \pm 0.92$ & \\
Left photopic & & \\
Patient $(\mathrm{N}=30)$ & $4.28 \pm 0.95$ & \\
Control $(\mathrm{N}=46)$ & $3.81 \pm 0.77$ & \\
*p $<0.05 . \mathrm{SD}:$ standard deviation &
\end{tabular}

even pinpoint pupils develop in toxicity. ${ }^{16,17}$ However, the fact that opioids have different effects on pupil diameter (such as mydriatic effect in cats, miotic effect in dogs) among living organisms has brought many discussions. ${ }^{18-20}$ In conclusion, the effects of opioids on pupils are controversial and many hypotheses related to mechanism of action have been proposed. One of the current approaches to the effects of opioids on humans is described as follows: opioids cause respiratory depression, activate the parasympathetic system secondary to hypoxia and hypercarbia, resulting in miosis. ${ }^{18,21}$ There are also explanations that opioids cause miosis by reducing tonic inhibition of the occlamatory nucleus by reducing acetylcholine release in the periphery and central. ${ }^{22-24}$ As a result of these discussions, it was concluded that the miotic effect was not only associated with parasympathetic stimulation; The hypothesis that opioids can induce a local effect by directly stimulating EdingerWestphal nucleus has also been proposed. ${ }^{25}$

The most important finding of this study is that the photopic values of the subjects who were followed up with OUD diagnosis in the past were higher than the healthy subjects. Normally; in bright environments, miotic effect is observed with parasympathetic activation of the pupils. In the patient group not under opioid effect, a miotic effect is expected in the bright setting. However, mydriatic reaction was observed in these patients. In other words, photopic pupil diameters were found to be wider than controls. In fact, the sympathet-

Table 4. Pupil diameters of cannabis and control groups

\begin{tabular}{lll}
\hline \multicolumn{1}{c}{ Parameter } & Mean \pm SD & p value \\
\hline Right scotopic & & 0.696 \\
Patient $(\mathrm{N}=31)$ & $5.84 \pm 1.11$ & \\
Control $(\mathrm{N}=46)$ & $5.77 \pm 0.94$ & 0.082 \\
Right mesophic & & \\
Patient $(\mathrm{N}=31)$ & $5.27 \pm 1.07$ & \\
Control $(\mathrm{N}=46)$ & $4.94 \pm 1.02$ & \\
Right photopic & & \\
Patient $(\mathrm{N}=31)$ & $4.23 \pm 0.881^{*}$ \\
Control $(\mathrm{N}=46)$ & $3.73 \pm 0.74$ & 0.522 \\
Left scotopic & & \\
Patient $(\mathrm{N}=31)$ & $5.45 \pm 1.15$ & 0.099 \\
Control $(\mathrm{N}=46)$ & $5.32 \pm 1.06$ & \\
Left mesophic & & \\
Patient $(\mathrm{N}=31)$ & $4.97 \pm 1.10$ & $0.049^{*}$ \\
Control $(\mathrm{N}=46)$ & $4.68 \pm 0.92$ & \\
Left photopic & & \\
Patient $(\mathrm{N}=31)$ & $4.10 \pm 0.83$ & \\
Control $(\mathrm{N}=46)$ & $3.81 \pm 0.77$ & \\
*p $<0.05 . \mathrm{SD}:$ standard deviation &
\end{tabular}


Table 5. Pupil diameters of multiple substance use group and control groups

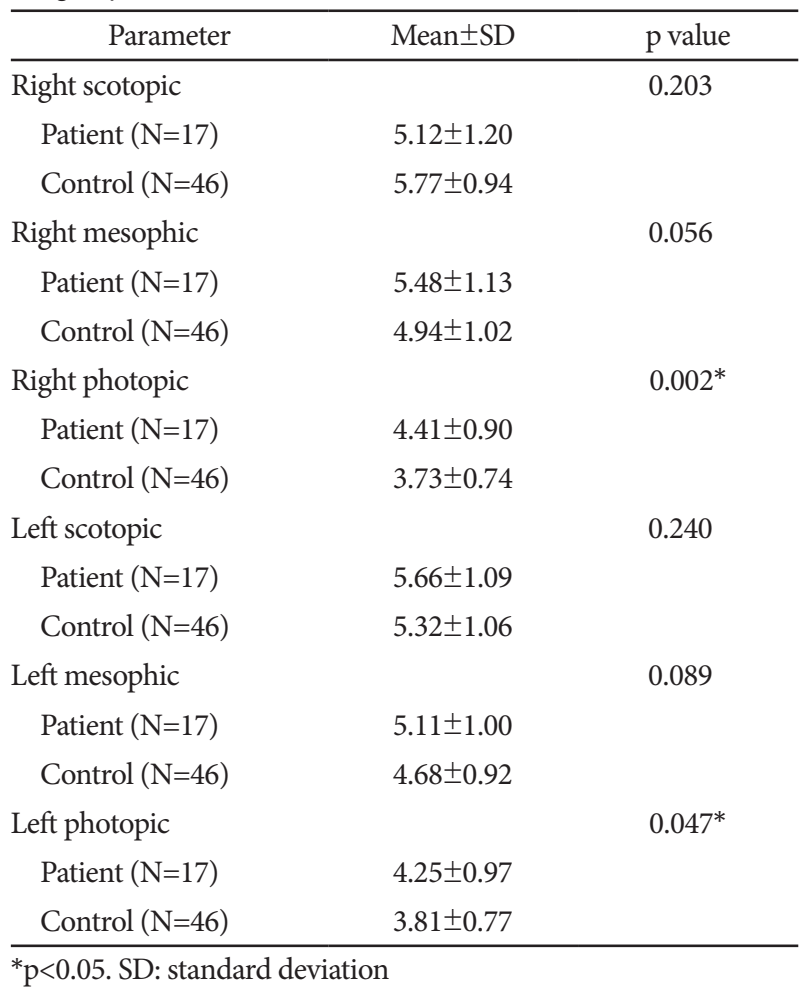

ic-parasympathetic hierarchy was thought to be impaired in patients with increased sympathetic system activation due to long-term opioid use. Activation of the reflex parasympathetic system led to the idea that sympathetic activation was desensitized over time. ${ }^{14}$

As in the OUD group, photopic pupil diameters were significantly higher in the CUD group than in the controls. This made us think that the sympathetic response to light was diminished. There are conflicting findings regarding the effects of cannabis on pupil diameter. Some studies show that cannabis use causes dose-related miosis. In addition, cannabis use has been shown to reduce response to light reflex and cause pupil diameter to shrink. ${ }^{9,10}$ On the other hand, there are studies reporting mydriatic effect due to chronic cannabis. ${ }^{26}$ Merzouki et al. ${ }^{27}$ reported that short term use of cannabis causes mydriasis as a result of parasympatholysis secondary to adrenergic stumulation. It is also thought that cannabis use can cause pupillary dilatation through cannabinoid type 1 (CB1) receptors found in human retina. ${ }^{28}$ In our study, mydriatic effect was seen in patients with a history of chronic cannabis use and who are currently in remission. This effect was significant in photopic measurements. This is thought to result from reflex parasympathetic effect secondary to chronic adrenergic stimulation.

Ecstasy, which contains 3, 4-methylenedioxy-N-methylamphetamine as active substance, increases noradrenaline, sero-
Table 6. Pupil diameters of ecstasy and control groups

\begin{tabular}{lll}
\hline Parameter & Mean \pm SD & p value \\
\hline $\begin{array}{l}\text { Right scotopic } \\
\text { Patient }(\mathrm{N}=32)\end{array}$ & 0.320 \\
Control $(\mathrm{N}=46)$ & $5.77 \pm 0.94$ & \\
Right mesophic & & 0.088 \\
Patient $(\mathrm{N}=32)$ & $5.30 \pm 1.12$ & \\
Control $(\mathrm{N}=46)$ & $4.94 \pm 1.02$ & \\
Right photopic & & \\
Patient $(\mathrm{N}=32)$ & $4.30 \pm 0.88$ & \\
Control $(\mathrm{N}=46)$ & $3.73 \pm 0.74$ & \\
Left scotopic & & \\
Patient $(\mathrm{N}=32)$ & $5.43 \pm 1.13$ & \\
Control $(\mathrm{N}=46)$ & $5.32 \pm 1.06$ & 0.118 \\
Left mesophic & & \\
Patient $(\mathrm{N}=32)$ & $4.98 \pm 1.08$ & \\
Control $(\mathrm{N}=46)$ & $4.68 \pm 0.92$ & \\
Left photopic & & \\
Patient $(\mathrm{N}=32)$ & $4.16 \pm 0.86$ & \\
Control $(\mathrm{N}=46)$ & $3.81 \pm 0.77$ & \\
\hline
\end{tabular}

${ }^{*} \mathrm{p}<0.05$. SD: standard deviation

tonin and dopamine levels in the synaptic range. Although the effects of these substances on pupil diameter are not clearly known, the miotic effect can be expected when used because they are stimulants that activate the parasympathetic system. ${ }^{29}$ In our study, photopic values were higher in patients with a history of stimulant use than in healthy controls. This is thought to result from reflex parasympathetic effect secondary to chronic adrenergic stimulation.

Normally, opioids cause miosis. This is a sign of an opioid overdose. This is the acute effect of opioid use. Studies on pupil diameter values of persons with a history of chronic substance use but currently in remission (clean for last 8 weeks or without acute opiod effect) are unknown. This study was conducted to illuminate this area where data is limited. The most important topic of this study is that pupils' response to light is permanently impaired in persons with a history of chronic substance use. In all of our patients, it was observed that the sympathetic response to light was lost, the parasympathetic system function was impaired and continuously activated, and the sympathetic-parasympathetic hierarchy was disrupted. In particular, it has been observed that photopic vision is impaired. It is observed that myriatic response develops in cases where normal miotic effect is required.

In conclusion, studies have shown that mydriatic pupil can cause glaucoma in the eye in the long term. Long-term mydriasis may result in thickening of the iridocorneal angle of 
the iris periphery, preventing drainage of the humorous aqueous. There are also studies suggesting that many psychiatric drugs may have a role in the development of glaucoma. Tricyclic antidepressants and selective serotonin reuptake inhibitors used in the treatment of SUD cause mydriasis and they cause relative blockade in the anterior chamber and increase intraocular pressure with their anticholinergic, noradrenergic and serotonergic effects. These drugs lead to relaxation of the iris pupillary sphincter (passive mydriasis) through 5-HT7 receptors. In addition, they can cause glaucoma by directly affecting the production of humorous aqueous by acting on the 5-HT2A and 5-HT2C receptors in the ciliary body. Indeed, in patients with chronic mydriatic response, mydriasis may trigger glaucoma by increasing intraocular pressure and choroidal effusion. Another undesirable outcome is cataract development. It is thought that the sensitivity of the mydriatic pupils to light will increase and by passing more light to the lens, it will trigger opacity in the lens and cause cataract development. In clinical practice, morphine derivatives can be used as analgesics and cannabinoid derivatives can be used in the treatment of neuropathic pain, multiple sclerosis, anxiety, nausea and vomiting. Considering the clinical use of these substances, it is thought that unknown long-term effects should be clarified. ${ }^{30,31}$

The major limitation of this study is its cross-sectional design. There is a need for study that equals male and female subjects and control numbers. Past and current drug use of the study group was unknown. In addition, pupil diameter data were not evaluated separately due to insufficient number of amphetamine and alcohol groups.

\section{Acknowledgments}

We thank all our colleagues from the Department of Psychiatry and Ophthalmology of the hospital for their support and assistance in this study.

\section{Conflicts of Interest}

The authors have no potential conflicts of interest to disclose.

\section{Author Contributions}

Conceptualization: Oguzhan Bekir Egilmez, Aysun Kalenderoglu, Mehmet Hamdi Orum. Data curation: all authors. Formal analysis: Oguzhan Bekir Egilmez, Aysun Kalenderoglu, Mehmet Hamdi Orum. Funding acquisition: Oguzhan Bekir Egilmez. Investigation: Mehmet Hamdi Orum, Ali Kustepe, Ayse Sevgi Karadag. Methodology: Aysun Kalenderoglu, Oguzhan Bekir Egilmez, Mehmet Hamdi Orum. Project administration: Oguzhan Bekir Egilmez. Resources: Ali Kustepe, Mehmet Hamdi Orum, Ayse Sevgi Karadag. Software: Mehmet Hamdi Orum. Supervision: Ayse Sevgi Karadag, Aysun Kalenderoglu. Validation: Aysun Kalenderoglu. Visualization: Mehmet Hamdi Orum. Writing_original draft: Aysun Kalenderoglu, Mehmet Hamdi Orum. Writing_-review \& editing: Mehmet Hamdi Orum.

\section{ORCID iDs}

Oguzhan Bekir Egilmez Mehmet Hamdi Orum Ali Kustepe https://orcid.org/0000-0002-6303-1758 https://orcid.org/0000-0002-4154-0738 https://orcid.org/0000-0001-9734-5360
Ayse Sevgi Karadag

https://orcid.org/0000-0002-7662-6531

Aysun Kalenderoglu https://orcid.org/0000-0002-8216-8610

\section{REFERENCES}

1. Boll F. On the anatomy and physiology of the retina. Vision Res 1977; 17:1249-1265.

2. Dowling JE. Retinal Neurophysiology. In: Albert DM, Jacobiec FA, Editors. Principles and Practice of Ophthalmology, 2nd Edition. Philadelphia, WB: Saunders, 2000, p.1713-1729.

3. Hendrickson AE. Morphological Development of the Primate Retina. In: Simons K, Editor. Early Visual Development, Normal and Abnormal. New York, Oxford: Oxford University, 1993, p.287-295.

4. Hedges TR, Friedman DI, Horton JC, Newman SA, Striph HGG. Neuroophthalmology. In: Weingeist TA, Liesegang TJ, Grand MG, Editors. American Academy of Ophthalmology. San Francisco: AAO, 2000, p.97-100.

5. Glaser JS. The Pupils and Accommodations. In: Duane TD, Jaeger EA, Editors. Clinical Ophthalmology, Revised Edition. Philadelphia, WB: Harper \& Row, 1984, p.1-5.

6. Bienfang DC. Neuroophthalmology of the Pupil and Accommodation. In: Albert DM, Jacobiec FA, Editors.Principles and Practice of Ophthalmology. Philadelphia, WB: Saunders, 1994, p.2470-2472.

7. McDougall DH, Gamlin PD. Autonomic control of the eye. Compr Physiol 2015;5:439-473.

8. Szabadi E. Functional organization of the sympathetic control of the pupil. Front Neurol 2018;9:1069.

9. Stark MM, Englehart K, Sexton BF, Tunbridge R, Jackson P. Use of a pupillometer to assess change in pupillary size post-Cannabis. J Clin Med 2003;10:9-11.

10. Fant RV, Heishman SJ, Bunker EB, Pickworth WB. Acute and residual effects of marijuana in humans. Pharmacol Biochem Behav 1998;60: 77-84.

11. Brown B, Adams AJ, Haegerstrom-Portnoy G, Jones RT, Flom MC. Pupil size after use of marijuana and alcohol. Am J Ophthalmol 1977;83: 350-354.

12. Bramness JG, Khiabani HZ, Mørland J. Impairment due to cannabis and ethanol: clinical signs and additive effects. Addiction 2010;105:10801087.

13. Weinhold LL, Bigelow GE. Opioid miosis: effects of lighting intensity and monocular and binocular exposure. Drug Alcohol Depend 1993;31: 177-181.

14. Pickworth WB, Welch P, Henningfield JE, Cone EJ. Opiate-induced pupillary effects in humans. Method Find Exp Clin 1989;11:759-763.

15. American Psychiatric Association. Diagnostic and Statistical Manual of Mental Disorders, 5th Ed. Washington, DC: American Psychiatric Association Publishing; 2013.

16. Knaggs RD, Crighton IM, Cobby TF, Fletcher AJ, Hobbs GJ. The pupillary effects of intravenous morphine, codeine, and tramadol in volunteers. Anesth Analg 2014;99:108-112.

17. Larson MD. Mechanism of opioid-induced pupillary effects. Clin Neurophysiol 2008;119:1358-1364.

18. Zhao D, Weil MH, Tang W, Klouche K, Wann SR. Pupil diameter and light reaction during cardiac arrest and resuscitation. Crit Care Med 2001;29:825-828

19. Murray RB, Loughnane MH. Infrared video pupillometry: a method used to measure the pupillary effects of drugs in small laboratory animals in real time. J Neurosci Methods 1981;3:365-375.

20. Sharpe LG, Pickworth WB. Pharmacologic evidence for a tonic muscarinic inhibitory input to the Edinger-Westphal nucleus in the dog. Exp Neurol 1981;71:176-190.

21. Rollins MD, Feiner JR, Lee JM, Shah S, Larson M. Pupillary effects of high-dose opioid quantified with infrared pupillometry. Anesthesiology 2014;121:1037-1044.

22. Domino EF, Wilson A. Effects of narcotic analgesic agonists and antag- 
onists on rat brain acetylcholine. J Pharmacol Exp Ther 1973;184:18-32.

23. Jhamandas K, Sutak M, Bell S. Modification of precipitated morphine withdrawal syndrome by drugs affecting cholinergic mechanisms. Eur J Pharmacol 1973;24:296-305.

24. Yaksh TL, Yamamura HI. Depression by morphine of the resting and evoked release of $[3 \mathrm{H}]$-acetylcholine from the cat caudate nucleus in vivo. Neuropharmacology 1977;16:227-233.

25. Gutstein HB, Akil H. Opioid Analgesics. In: Brunton LL, Lazo JS, Parker KL, Editors. Goodman and Gilman's the Pharmacological Basis of Therapeutics, 11th Edition. New York: McGraw-Hill Companies, Inc, 2010, p.547-590.

26. Raman SV, Jacob J. Mydriasis due to Datura inoxia. Emerg Med J 2005; 22:310-311.
27. Merzouki A, Mesa JM, Louktibi A, Kadiri M, Urbano GV. Assessing changes in pupillary size in Rifian smokers of kif (Cannabis sativa L.). J Forensic Leg Med 2008;15:335-338.

28. Straiker AJ, Maguire G, Mackie K, Lindsey J. Localization of cannabinoid CB1 receptors in the human anterior eye and retina. Invest Ophthalmol Vis Sci 1999;40:2442-2448.

29. Zawilska JB, Andrzejczak D. Next generation of novel psychoactive substances on the horizon-A complex problem to face. Drug Alcohol Depen 2015;157:1-17.

30. Richa S, Yazbek JC. Ocular adverse effects of common psychotropic agents: a review. CNS Drugs 2010;24:501-526.

31. Salmon JF. Predisposing factors for chronic angle-closure glaucoma. Prog Retin Eye Res 1999;18:121-132. 